\title{
Cooperative Performance of Green Assembly Structures Based on Dry Connections and Energy Extraction Mechanism
}

\author{
Zhang Jiarui \\ Xi'an University of Architecture and Technology, Xi'an, China
}

Keywords: dry connection; assembly structure; fan lead sticky; hybrid assembly structure.

\begin{abstract}
This paper introduces the latest progress in seismic research of precast concrete frame structures, including precast concrete frame prestressed splice joints, post-poured integral joints, fully assembled joints and seismic research of assembled concrete frame structures. The aseismic performance of all kinds of joints in assembled concrete frame structures is summarized. It is pointed out that the aseismic performance of all assembled joints and prefabricated structures is the content that needs further study in the future. Green assembling structure based on dry connection is highly praised in our country, and the research of joint especially beam-column joint is the key to promote the development and application of this kind of structure. In this paper, fan-shaped lead viscoelastic dampers and post-tensioned unbonded composite frame joints are arranged at beam-column joints. The three methods can effectively improve the seismic performance of members.
\end{abstract}

\section{Introduction}

The fabricated reinforced concrete structure is one of the important directions of building structure development in China. It is conducive to the development of building industrialization, improving production efficiency, saving energy, developing green environmental protection buildings, and improving and ensuring the quality of construction projects. Compared with the cast-in-situ construction method, the assembled RC structure is beneficial to the green construction because the assembled construction can meet the requirements of the green construction, such as saving energy, saving material, saving water and environmental protection, and reduce the negative impact on the environment, including reducing noise, preventing dust, reducing environmental pollution, cleaning transportation and reducing site dryness. Harming, saving water, electricity, materials and other resources and energy, and following the principle of sustainable development. Moreover, the assembled structure can continuously complete many or all working procedures of the project in sequence, thereby reducing the type and quantity of construction machinery entering the site, eliminating the idle time of working procedure connection, realizing the intersection operation, reducing the construction personnel, thereby improving the work efficiency, reducing material consumption, reducing environmental pollution, and implementing green construction. Workers provide protection. In addition, the assembled structure to a large extent to reduce construction waste (about 30\% - 40\% of the total urban waste), such as waste steel, waste wire, waste bamboo wood, waste concrete. Domestic and foreign scholars have done a lot of research work on the prefabricated RC structure, and developed a variety of prefabricated structure forms, such as unbonded prestressed prefabricated frame, mixed connection prefabricated concrete frame, prefabricated steel fiber reinforced high-strength concrete frame, prefabricated integral steel reinforced concrete frame and so on. However, due to the lack of understanding of seismic performance of precast concrete structures in China, the research and engineering application of precast concrete structures still lag far behind the advanced level of foreign countries, and the application of precast concrete structures in earthquake areas is limited. Therefore, it is urgent for China to develop a system of seismic performance of precast concrete structures. Unified research. 


\section{Optimal design and seismic performance of 2 fabricated beam column joints}

\subsection{ECC material}

ECC (Engineered cementitious composites) is a kind of fiber reinforced cement matrix composites with ultra-high toughness and superior energy dissipation properties. Its application in engineering structures can greatly improve the seismic performance of components. The results show that the tensile strength of ECC is similar to that of metal materials. The ultimate tensile strain of ECC can reach 5\% 6\%, which is almost the same as that of steel. Especially ECC has embarked on the road of green, through the effective combination of fiber and active admixture, has further strengthened the key performance of concrete materials, greatly improved the durability, and extended the service life of materials and structures.

ECC was first proposed by Professor Victor C.Li of Michigan University in the early 1990s. It is based on the principle of micro-mechanics to improve the interaction between fiber and matrix in cement-based materials and between them at the interface. The basic properties of composites with cement mortar or mortar as matrix and fiber as reinforcing material are studied. As shown in Table 1.

Table 1 basic properties of ECC materials

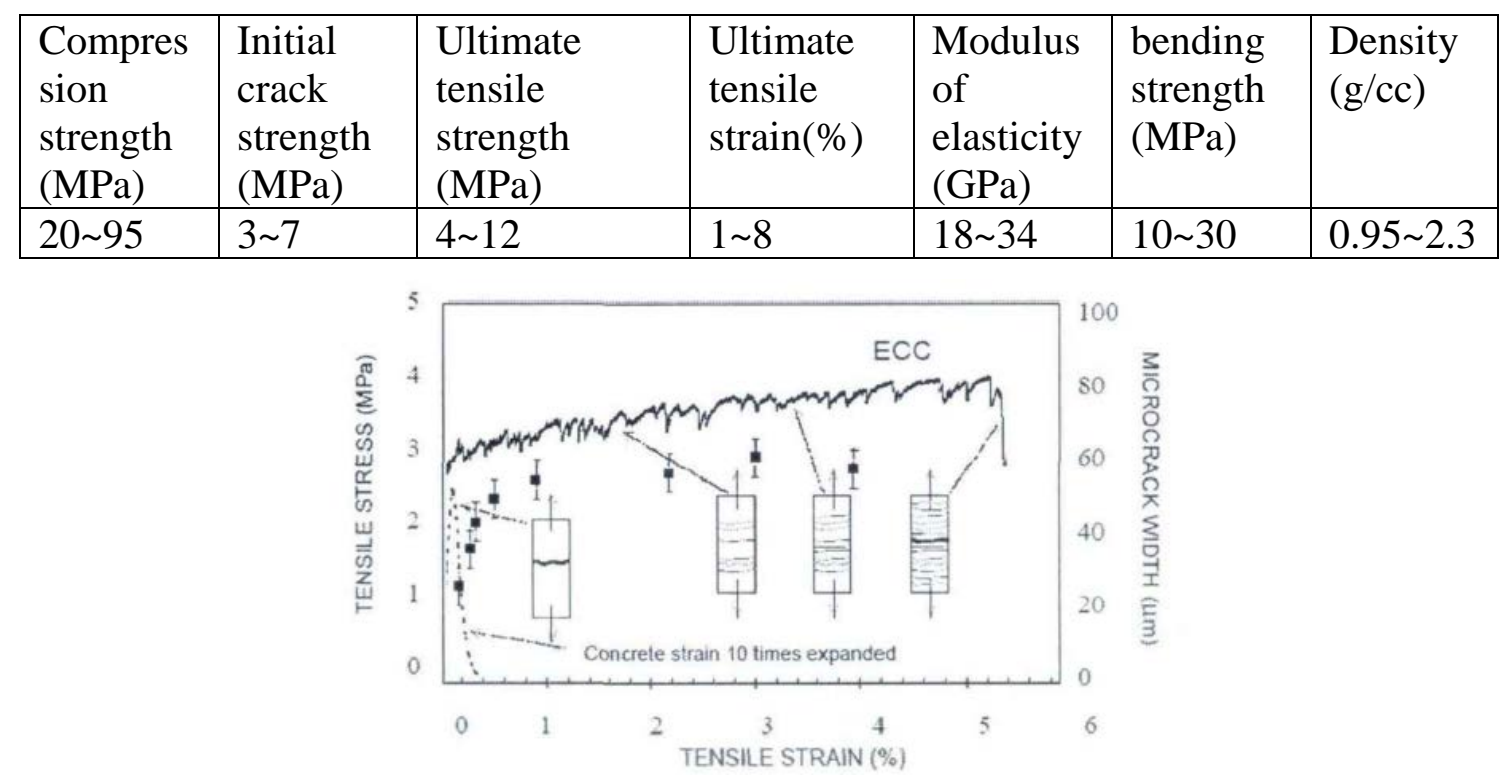

Fig. 1 ECC uniaxial tensile stress-strain curve

Fig. 1 is a typical stress-strain curve for uniaxial tension of ECC. It can be seen from the diagram that ECC exhibits high ductility (about 5\% ultimate tensile strain), fine and dense cracks, strain hardening characteristics similar to metals in the later stage of elastic segment, and softening behavior after peak point.

Liang Xingwen and Deng Mingke proposed ECC as a new type of anti-collapse structure, that is, using high-performance ECC to improve the deformation, loss and damage resistance of components and structures in key parts of the structure. For example, under strong earthquake, the well-designed coupling shear wall should yield first to the coupling beam, and then to the bottom of the shear wall. Therefore, the key parts of the coupled shear wall structure are the coupling beam and the bottom of the wall limb. In order to facilitate construction, R / ECC prefabricated members are used for connecting beams, cast-in-situ R / ECC is used at the bottom of wall legs, and cast-in-situ R / C is used at other parts to form a new type of seismic wall structure.

The results show that the hysteretic curves of the specimens with ECC post-pouring are fuller and have better energy dissipation capacity. In addition, the stirrup stress level of ECC specimens is lower than that of concrete specimens under the same load level, indicating that ECC can share part of the shear force and can partly replace the stirrup. ECC uniaxial constitutive model in OpenSees 
platform can simulate the seismic behavior of reinforced concrete flexural members better: with the increase of ECC strength, the yield load and peak load of joint model will increase in varying degrees; the yield load and peak load of post-poured ECC model will be higher than that of post-poured concrete model under the same compressive strength of matrix material. The reduction of ECC elastic modulus has an effect on the initial stiffness and strength of the joints, but has little effect.

For the application of ECC materials, there are still some questions to be further studied.

(1) Develop and produce high-performance, low cost PVA fibers suitable for engineering applications.

(2) The basic properties of ECC materials. For structural analysis and design, the compressive strength, tensile strength, peak strain, ultimate strain and constitutive relationship of ECC materials must be studied and solved.

(3) The basic performance of R/ECC components of ECC material is studied in key parts. For example, the bearing capacity, deformation calculation, ductility and energy dissipation capacity of beams, column ends and joints with ECC materials.

(4) The key part is the new energy dissipation and seismic failure mechanism and design method of R/ECC components.

\subsection{Sector lead viscoelastic dampers}

Dampers are mainly used for shock absorption or shock prevention, allowing movement at low speeds, locking at speeds or accelerations exceeding the corresponding values, forming rigid support. The main categories are: spring dampers, hydraulic dampers, pulse dampers, rotary dampers, and viscoelastic dampers. The viscoelastic damper is a very effective and safe energy dissipation device. As a composite damper, lead viscoelastic dampers utilize plastic deformation and energy dissipation of shear hysteretic deformation of viscoelastic materials after shear or extrusion yielding of lead.

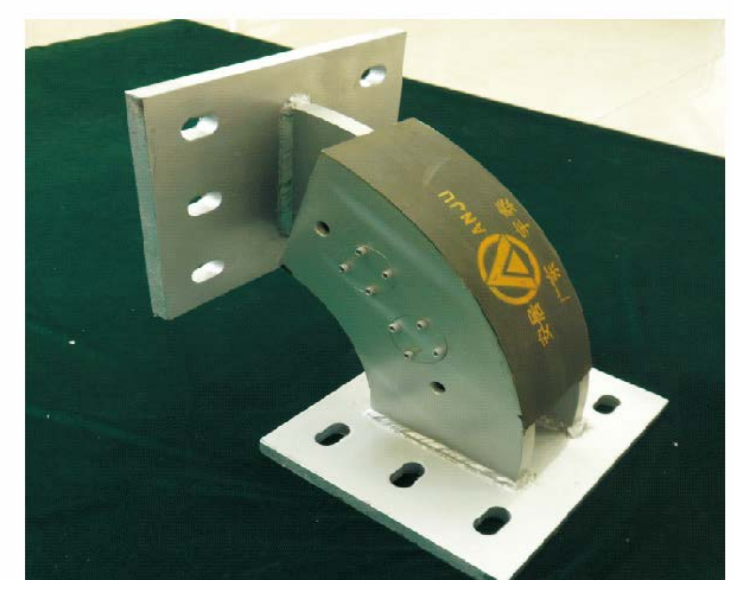

Fig. 2 sector lead viscoelastic dampers

The Sector Lead Viscoe.c Damper, SLVD) is the the providers of the providers to the providers to the providers, and the.to the providers to the damper, and it is the providers to the damper, and the providers to the providers, the providers, and the providers, the providers, the function, theFor example.It's the default, you can can be be be be be be the example of the default, and the default, and the default, and the default, and the default, and the default, and the default, and the default, the default, the default, and the default, the default, the default.

Wu Congxiao, Zhou Yun, Zhang Chao and so on. In order to further study the influence of fan-shaped lead viscoelastic dampers on seismic behavior of beam-column joints of prefabricated fabricated frames, the cast-in-place frame joints with fan-shaped lead viscoelastic dampers and the $1 / 3$ scale model of prefabricated frame joints were set up at beam-column joints. The failure modes of the two joints were compared and studied. Formulas, hysteretic energy dissipation performance, bearing capacity, displacement ductility, bearing capacity degradation and steel bar strain in the core 
area of the joint, etc. It is concluded that the sector-shaped lead viscoelastic damper changes the stress mode of precast and cast-in-situ specimens, slows down and controls the crack development in the core area of the specimens, and protects the joints. The finite element analysis is carried out.

Zhu Yanjie and Zhou Yun used ETABS and Perform-3D software to design and analyze the energy dissipation and seismic response of the structure with sector lead viscoelastic dampers. The results show that the use of sector lead viscoelastic dampers can significantly reduce the seismic response of the structure and reduce the internal force at the joints of the frame under frequent and rare earthquakes. Under frequent earthquakes and rare earthquakes, the relevant codes and performance requirements can be met.

Fan-shaped lead viscoelastic damper is a new type of beam-column axillary braced damper. Its application is not limited by structure and environment. The current research is still in its infancy. There are still some problems to be studied.

(1) There is a lack of energy dissipation and seismic design method for new type of sector lead viscoelastic damper to ensure that the design parameters of the damper can be determined quantitatively in practical engineering.

(2) Lower-cycle tests were carried out on the frame with sector-shaped lead viscoelastic dampers to study the failure modes, skeleton curves and energy dissipation capacity of the original frame structure.

\subsection{Post tensioned unbonded hybrid assembly frame joint}

The prefabricated prestressed concrete frame structure is a kind of structure which carries the prefabricated beams and columns to the construction site, hoists the components in place by hoisting machinery, penetrates the prestressed reinforcement in the reserved channel of the beams and columns, and assembles the beams and columns into the whole frame by the extrusion force of the post-tensioned prestressed reinforcement. Post-tensioned tendons can not only be used as a means of assembling and connecting members in the construction stage, but also bear the bending moment at the end of the beam in the use stage, forming the whole stress node and continuous stress frame. This connection between prefabricated members is called prestressed connection mode, which belongs to "dry connection" and "ductile connection". Category. The structural system formed by introducing post-tensioned tendons into precast concrete frame structures has the advantages of ordinary precast concrete structures as well as the following characteristics:

(1) it is easy to realize the energy dissipation mechanism of beam hinge.

(2) it is easy to assess structural damage caused by earthquakes.

(3) the structure has good recovery performance, small residual deformation and easy to repair.

Priestley, of the University of California, made a theoretical study of partially bonded prestressed spliced joints [2]. He pointed out that because the prestressed tendons do not bond to concrete within the joints and at both sides of the joints within a certain range, the prestressed tendons can still remain elastic when the joints undergo large deformation. The strength and stiffness attenuation and residual deformation of the joint after large deformation are small, and the joint has a strong resilience; due to the clamping restraint effect of prestress, it is advantageous to the shear resistance of the joint area and can reduce the amount of stirrups in the joint area. Priestley tests were carried out on 8 unbonded prestressed beam column joints under cyclic loading. The test results show that the maximum interlaminar deformation of the joints is $2.8 \% \sim 4 \%$, and the residual deformation is about $2.2 \%$ of the maximum interlaminar deformation. Compared with the cast-in-situ concrete joints, the unbonded prestressed joints of precast concrete consume less energy, and have less damage, strength loss and residual deformation.

From the experience summarized by the predecessors, it can be seen that the post-earthquake repairing work and self-repairing ability of the assembled unbonded prestressed concrete frame structure system have obvious advantages over the cast-in-situ structure, but the following aspects need to be further studied: the ground of the assembled unbonded prestressed concrete frame structure system Seismic energy dissipation capacity is poor, so we can consider the introduction of isolation or shock absorption devices to improve its energy dissipation capacity. The influence of 
mortar strength and joint width on the seismic capacity of the structure is considered.

\section{Conclusion}

Earthquake is a natural disaster that seriously endangers human life and property. China is a country with many earthquakes. Since the 1960s, China has suffered many earthquake disasters. The accumulation of earthquake damage experience and the implementation of building seismic design code have played a certain role in building seismic disaster reduction. Building and various engineering structures are the basic places and infrastructures for people to engage in life and production activities, and their safety, especially aseismic capacity, must be fully guaranteed. Reducing and avoiding the damage of buildings and all kinds of engineering structures caused by earthquakes has become one of the most important research directions of engineering structure safety and disaster prevention and mitigation in China.

\section{References}

[1] Singh M, Liebrand J, Joshi D. Cultivating “success" and "failure” in policy: participatory irrigation management in Nepal[J]. Development in Practice, 2014, 24(2):155-173.

[2] Sheu J B, Chen Y J. Impact of government financial intervention on competition among green supply chains[J]. International Journal of Production Economics, 2012, 138(1):201-213.

[3] Li X. Methods to evaluate the performance of multiple uncooperative users for green cognitive radio networks[C]// Online Conference on Green Communications. IEEE, 2014:38-42.

[4] Prema G, Narmatha D. Performance of energy aware cooperative spectrum sensing algorithms in cognitive wireless sensor network[C]// Online International Conference on Green Engineering and Technologies. IEEE, 2017:1-6. 